\title{
No miRNA were found in Plasmodium and the ones identified in erythrocytes could not be correlated with infection Xiangyang Xue ${ }^{1}$, Qingfeng Zhang ${ }^{1}$, Yufu Huang ${ }^{2}$, Le Feng ${ }^{1}$ and Weiqing $\operatorname{Pan}^{* 1,2}$
}

\author{
Address: ${ }^{1}$ Institute for Infectious Diseases and Vaccine Development, Tongii University College of Medicine, 1239 Siping Road, Shanghai 200092 \\ China and 2Department of Pathogenic Biology, Second Military Medical University, 800 Xiang Yin Road, Shanghai 200433, China \\ Email: Xiangyang Xue -wzxxy@yahoo.com.cn; Qingfeng Zhang - qinf_zhang@yahoo.com.cn; Yufu Huang - yufuhu0725@yahoo.com.cn; \\ Le Feng - fengle1126@163.com; Weiqing Pan* -wqpan0912@yahoo.com.cn \\ * Corresponding author
}

Published: 10 March 2008

Malaria Journal 2008, 7:47 doi:10.1 186/1475-2875-7-47
Received: 20 September 2007

Accepted: 10 March 2008

This article is available from: http://www.malariajournal.com/content/7///47

(c) 2008 Xue et al; licensee BioMed Central Ltd.

This is an Open Access article distributed under the terms of the Creative Commons Attribution License (http://creativecommons.org/licenses/by/2.0), which permits unrestricted use, distribution, and reproduction in any medium, provided the original work is properly cited.

\begin{abstract}
Background: The transcriptional regulation of Plasmodium during its complex life cycle requires sequential activation and/or repression of different genetic programmes. MicroRNAs (miRNAs) are a highly conserved class of non-coding RNAs that are important in regulating diverse cellular functions by sequence-specific inhibition of gene expression. What is know about double-stranded RNA-mediated gene silencing (RNAi) and posttranscriptional gene silencing (PTGS) in Plasmodium parasites entice us to speculate whether miRNAs can also function in Plasmodium-infected RBCs.
\end{abstract}

Results: Of 132 small RNA sequences, no Plasmodium-specific miRNAs have been found. However, a human miRNA, miR-45I, was highly expressed, comprising approximately one third of the total identified miRNAs. Further analysis of miR-45I expression and malaria infection showed no association between the accumulation of miR-45I in Plasmodium falciparum-iRBCs, the life cycle stage of $P$. falciparum in the erythrocyte, or of $P$. berghei in mice. Moreover, treatment with an antisense oligonucleotide to miR-45I had no significant effect on the growth of the erythrocyticstage $P$. falciparum.

Methods: Short RNAs from a mixed-stage of $P$. falciparum-iRBC were separated in a denaturing polyacrylamide gel and cloned into $T$ vectors to create a cDNA library. Individual clones were then sequenced and further analysed by bioinformatics prediction to discover probable miRNAs in $P$. falciparum-iRBC. The association between miR-45I expression and the parasite were analysed by Northern blotting and antisense oligonucleotide (ASO) of miR-45I.

Conclusion: These results contribute to eliminate the probability of miRNAs in $P$. falciparum. The absence of miRNA in P. falciparum could be correlated with absence of argonaute/dicer genes. In addition, the miR-45I accumulation in Plasmodium-infected RBCs is independent of parasite infection. Its accumulation might be only the residual of erythroid differentiation or a component to maintain the normal function of mature RBCs. 


\section{Background}

MicroRNAs (miRNAs), a newly discovered class of endogenous 21 nucleotide regulatory non-coding small RNAs, post-transcriptionally regulated gene expression in eukaryotes by targeted RNA degradation and translational arrest [1]. Similarly to short interfering RNAs (siRNAs), miRNAs are produced in the cytoplasm from a precursor, which contains an imperfectly matched inverted repeat forming a partial double-stranded region, by the ribonuclease, dicer. One strand of the resulting miRNA duplex intermediate is then recruited by the argonaute nuclease, an enzyme involved in the silencing mechanism, and incorporated into the RNA-induced silencing complex (RISC). The mature single-stranded miRNA guides the target RISC to bind to the 3' untranslated regions of target mRNAs based on sequence complementarity, which are then degraded and/or translationally inhibited. Since the discovery of the founding members of the miRNA family, lin-4 and let-7[2,3], hundreds of miRNAs had been identified in viruses, plants, and animals by molecular cloning and bioinformatic approaches [4-7].

The malaria parasite Plasmodium falciparum is a eukaryote with a complex life cycle in two hosts and a unique repertoire of proteins expressed at distinct life cycle stages. Its genome is strikingly A-T rich $(80 \%-90 \%)[8,9]$. The paucity of annotated transcription factors and the phased expression of blood stage transcripts have led to the proposal that post-transcriptional gene silencing is an important mechanism in the regulation of gene expression in Plasmodium [10]. Moreover, the phenomenon of doublestranded RNA-mediated gene silencing (RNAi) in the Plasmodium parasite had been reported in several studies [1115]. In addition, 21 nucleotide siRNAs were found in other protozoa such as Tetrahymena thermophila, Trypanoma brucei, and Entamoeba histolytica[16,17]. In Entamoeba histolytica, the presence of siRNAs was investigated, and seventeen putative miRNA candidates were identified by bioinformatics methods [18]. However, bioinformatics analysis of the $P$. falciparum genome showed that the genes encoding dicer and argonaute, which are crucial components in the RNAi pathway and play a key role in miRNA biogenesis and functional pathways, were absent $[10,19,20]$.

In this study, a possibility of the miRNAs present in $P$. falciparum was investigated. Consistent with a recent report [21], P. falciparum-specific miRNAs were not found. However, Short RNAs from infected red blood cells (iRBCs), including miRNAs that matched human genomic sequences, particularly showed an abundant human miRNA in iRBC. The associations between the generation of these miRNAs and the infection of Plasmodium were explored.

\section{Methods}

\section{Parasites, animals, and reagents}

The 3D7 strain of $P$. falciparum was cultured in vitro using group O blood according to Trager's method[22]. A vial containing $P$. berghei ANKA strain frozen in liquid nitrogen was thawed quickly and injected intraperitoneally with $10^{7}$ parasitized erythrocyte into KM mice with age of $6 \sim 8$ weeks. When the parasitaemia in the mice reached approximately $10 \%$, the blood was harvested for detecting expression of miR-451. Thin blood smears were prepared to determine parasitaemia.

\section{Small RNA preparation, cloning and analysis}

The cloning and analysis of small RNAs was performed as described previously[5]. Briefly, total RNAs were isolated using Trizol reagent (Invitrogen) from a mixed-stage of the parasite including ring stage, trophazoite and schizoint when the parasitemia reached approximately $10 \%$, and short RNAs 18 to 25 nucleotides in length were purified by $15 \%$ PAGE with $8 \mathrm{M}$ urea. This approach is expected to clone all cellular miRNAs, including miRNAs from erythrocytes and Plasmodium, as well as any fragments of cellular mRNAs or noncoding RNAs that fall into this size range. After ligating $3{ }^{\prime}$ and 5 ' adapters (Takara, Dalian, China) to the small RNAs, the resultant miRNAs could be amplified by standard RT-PCR. The cDNAs then were concatenated, cloned and sequenced. The annotation was based on information from GenBank [23], a database of P. falciparum genome [24], a dataset of human tRNA sequences[25], and a database of miRNAs[26]. The genomic regions containing candidate sequences with $\sim 70$ bp flanking sequences were used to predict secondary structures using RNA-fold software such as Mfold[27].

\section{Northern blot analysis}

Total RNAs were subjected to electrophoresis on a $15 \%$ polyacrylamide gel under denaturing conditions, and the separated molecules were transferred electrophoretically to a Hybond-N nylon membrane (Pall-Gelman, USA). The membranes were hybridized with a biotin-labeled oligonucleotide probe (Invitrogen, Shanghai, China) corresponding to mature miRNA sequences. After incubation with streptavidin-horseradish peroxidase conjugate and an enhanced light-based chemiluminescent substrate detection system (Pierce), signals were detected by covering the membrane with plastic wrap and exposing to X-ray film.

\section{Synthesis and administration of miR-45 I antisense oligos (ASO)}

The unconjugated locked nucleic acids (LNA)-modified oligonucleotides (Sangon, Shanghai, China) were synthesized as the substitution of every third nucleotide position by LNA. The anti-miR-451 LNA oligonucleotide 5'-aaActCagTaaTggTaaCggTtt-3' (uppercase: LNA; lowercase: 
DNA) was complementary to the mature miR-451 sequence. The substance was formulated in RPMI 1640 medium containing $25 \mathrm{mM}$ HEPES, $24 \mathrm{mM}$ NaHCO3, and $15 \%$ (vol/vol) heat-inactivated rabbit serum to final concentration of 10,100,500 and $1000 \mathrm{nM}$ for P. falciparum cultivation. Highly-synchronized $P$. falciparuminfected erythrocytes were adjusted to the original culture with approximately $2 \%$ hematocrit and $0.5 \%$ parasitaemia. After incubating with different concentrations of the miR-451 ASO for $72 \mathrm{hr}$, thin blood smears were prepared to determine parasitaemia of each sample by counting the number of parasites in 2,000 erythrocytes.

\section{Results}

Cloning of short RNAs from P. falciparum-infected RBCs Total 132 short RNAs 18-26 nucleotides in length were obtained through cloning of cDNAs from P. falciparuminfected RBCs. Of the 132 short RNAs, 54 (40.91\%) were rRNAs and tRNAs from human blood and Plasmodium, 18 (13.64\%) were degraded fragments of human blood and Plasmodium mRNA, 36 (27.27\%) were human miRNAs, and $24(18.18 \%)$ did not match the human nor Plasmodium genome. Consistent with recent reports[21], no Plasmodium-specific miRNAs sequences were identified(Figure 1). The human miR-451 accumulated at a very high level, comprising almost $1 / 3$ of the identified miRNAs isolated from $P$. falciparum-iRBCs (Table 1).

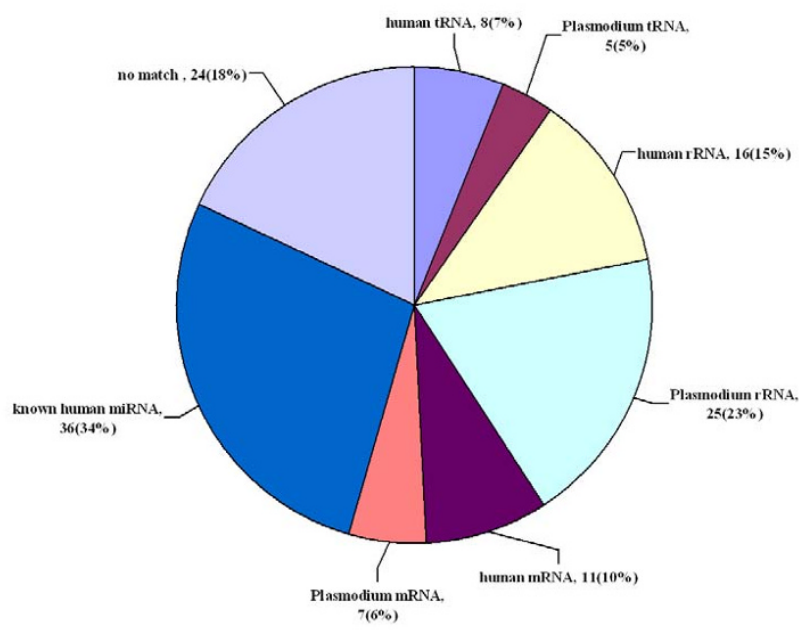

Figure I

Distribution of cloned short RNAs from $P$. falci-

parum-iRBC. One-hundred thirty-two short RNAs 18 to 26 nucleotides in length were isolated from $P$. falciparum-iRBCs and grouped according to sequence annotation (see Materials and Methods for details). Those with more than three mismatches to human or Plasmodium sequences were classified as ???.
Table I: Frequencies of known miRNAs identified from $P$. falciparum-iRBCs

\begin{tabular}{lcc}
\hline miRNAs & Number of clones & Percentage(\%) \\
\hline hsa-let-7a & $\mathrm{I}$ & 2.78 \\
hsa-let-7b & 7 & 19.44 \\
hsa-let-7f & 1 & 2.78 \\
hsa-mir-16 & 6 & 16.67 \\
hsa-mir-9I & 2 & 5.56 \\
hsa-mir-92 & 1 & 2.78 \\
hsa-mir-106 & 1 & 2.78 \\
hsa-mir-142 & 2 & 5.56 \\
hsa-mir-144 & 2 & 5.56 \\
hsa-mir-45 I & 14 & 38.89 \\
Total & 36 & 100 \\
\hline
\end{tabular}

Northern blot analysis confirmed the abundance of miR451 in Plasmodium-infected RBCs.

The association between miR-45 I expression level and the development of erythrocyte-stage $\mathbf{P}$. falciparum

The specificity of miR-451 expression was firstly investigated. To eliminate the possibility that the accumulated miR-451 in P. falciparum-iRBCs were derived from contamination by human white blood cells (WBCs), the transcription of miR-451 in parasite-iRBC and human WBCs was analysed by Northern blot. The result showed that miR-451 was transcribed at a very high level in $P$. falciparum-iRBCs, whereas no miR-451 transcripts were observed in human WBCs (Figure 2A).

The malaria parasite in infected erythrocytes has several developmental stages, including the early ring trophozoite, late trophozoite, and schizont. To investigate the association between the expression level of miR-451 and parasite development, the transcription of miR-451 at different development stages of synchronized $P$. falciparuminfected RBCs was assayed by Northern blot. Compared to equivalent amounts of total RNA $(2 \mu \mathrm{g})$ per lane, there were no significant difference in accumulated miR-451 transcription levels from rings to pigmented trophozoite stages. Moreover, when total RNA from equivalent numbers of erythrocytes was loaded, there was also no significant difference among them, although the transcription level of miR-451 seemed slightly lower in the next generation (cultivated after $72 \mathrm{~h}$ ) (Figure 2B).

To further analyse the potential functions of miR-451 in the development of erythrocyte-stage parasites, the Plasmodium-infected RBCs were synchronized and cultured in RPMI-1640 medium containing an ASO of miR-451 (Sangon, Shanghai, China)[22]. Different concentrations of the miR-451 ASO were added to the cultures and parasitaemias were determined. No interfering effect of the ASO 

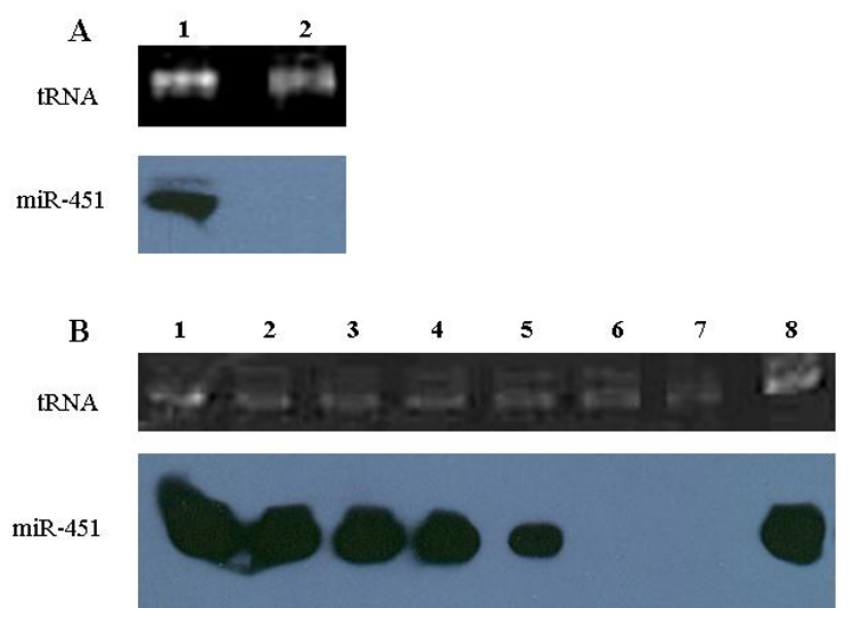

Figure 2

Detection of expression of miR-45 I by Northern blot. (A) Analysis of miR-45 I expression in human WBCs and $\boldsymbol{P}$. falciprum-iRBCs. Total RNA $(2 \mu \mathrm{g})$ from WBCs and $P$. falciprum-iRBCs was separated by denaturing PAGE and blotted to a nylon membrane. Biotin-labeled miR-45 I was used as a hybridization probe. Lane I, infected RBC; Lane 2, isolated WBCs. (B) Analysis of miR-45I expression in different erythrocytic-stage $P$. falciparumiRBCs. Total RNA $(2 \mu \mathrm{g})$ from known numbers of cells were prepared at $24 \mathrm{~h}$ intervals from a single tightly synchronized culture. Parasite stage was determined by thin blood smears. Lane I, healthy human RBCs; lane 2, 0-h culture after tight synchronization (ring-stage iRBCs); lane 3, 24-h culture (late trophozoite-stage iRBCs); lane 4, 48-h culture (schizont-stage iRBCs); lane 5, 72-h culture (new reproductive cycle of $P$. falciparum); lane 6, purified $P$. falciparum; lane 7 , purified $P$. falciparum treated with $\mathrm{RN}$ ase $\mathrm{H}$ to remove residual RNA contamination; lane 8, 72-h culture of $P$. falciparumiRBCs loaded with equivalent numbers of erythrocytes as lane 2.

of miR-451 on the parasite growth was observed compared to the untreated group.

\section{Expression of miR-45I in P. berghei-infected mouse erythrocytes}

In addition to Homo sapiens, miR-451 is also expressed in other species, such as Mus musculus, Rattus norvegicus, Danio rerio, Xenopus tropicalis, Gallus gallus, and Monodelphis domestica [26]. In this study, the expression of miR451 in the blood of KM mice was confirmed by Northern blot analysis (Figure 3). The investigation whether the expression of miR-451 could be influenced by Plasmodium infection in vivo was performed by using the P. berghei (ANKA strain) mice model. The results showed that miR451 expression, when comparing equivalent amounts of RNA, decreased slightly from lower to higher parasitaemia and became undetectable at $86 \%$ parasitaemia (Figure $3 \mathrm{~A})$. However, if the total RNAs loaded were adjusted
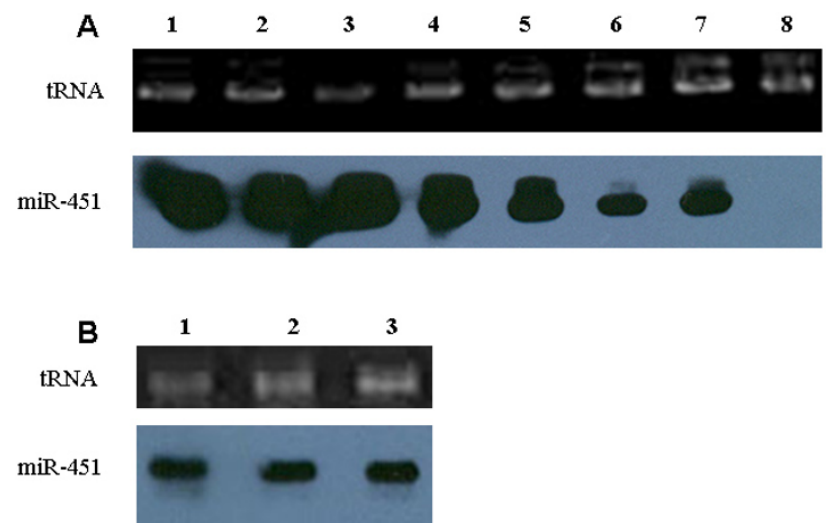

Figure 3

Analysis of $\mathrm{miR}-45 \mathrm{I}$ expression in the blood of $P$. berghei-infected KM mice at different parasitaemias. Female KM mice (6-8 weeks old) were infected with the blood stages of $P$. berghei (ANKA strain) by intraperitoneal injection of $10^{5}$ infected erythrocytes. The course of infection was monitored by examination of Giemsa-stained blood films. (A) Total RNAs from the whole blood of uninfected and infected mice with different parasitaemias were analysed by Northern blotting. Lane I, whole healthy blood; lane 2, $0.5 \%$ parasitaemia; lane 3, 2\% parasitaemia; lane 4, I2\% parasitaemia; lane 5, 28\% parasitaemia; lane 6, 43\% parasitaemia; lane 7, 60\% parasitaemia; lane 8, 86\% parasitaemia. (B) Total RNAs from equivalent numbers of blood cells $\left(10^{7}\right)$ with different parasitaemias were analysed by Northern blotting. Lane I, whole healthy blood; lane 2, 43\% parasitaemia; lane 3, $60 \%$ parasitaemia.

based on the number of blood cells, the difference in miR451 transcript level disappeared (Figure 3B). This indicated that the weak signal of the miR-451 transcript in samples with higher parasitaemia was due to dilution of parasite RNAs.

\section{Discussion}

Eukaryotes with a complex life cycle may be particularly likely to express miRNAs, as they could regulate their gene expression at different stages of their life cycle or affect host cell factors that increase the likelihood of maintaining long-term infection in the host. miRNAs from the host cell may also participate in the regulation of parasite gene expression even if Plasmodium cannot produce its own miRNAs. Therefore, miRNAs present in Plasmodiuminfected RBCs were examined by using a short RNA cloning approach. Similar to the results of Rathjen et al [21], no any Plasmodium-specific miRNAs was detected, further eliminating the probability of miRNAs in P. falciparum. If any regulatory RNAs exist in $P$. falciparum, they will be distinct from miRNAs. However, some known human miRNAs did isolate. Notably, the miRNA miR-451 accumulated to a very high level in infected RBCs, comprising more than one third of the cloned miRNAs. So the 
relationship between malaria infection and the expression of miR-451 were further explored.

The data presented here showed that accumulation of miR-451 in RBCs is unrelated to the life cycle of $P$. falciparum in the erythrocytic stage and parasitaemia in vivo, which suggested that the miR-451 expressed at high levels in RBCs is independent of parasite infection. The weaker expression of miR-451 in higher parasitaemia, as detected by Northern blotting, is due to dilution of parasite RNAs, because this difference was abolished after adjusting the total RNAs loaded based on the number of blood cells. In addition, an ASO against miR-451, which normally inhibits miRNA activity [28-30], had no observable effects on the growth of $P$. falciparum. Several potential explanations need to be addressed in future studies: (1) the ASO failed to diffuse into the RBCs, presumably due to their integration in the cell membrane of RBCs and the presence of nuclease in medium; (2) the accumulation of miR-451 to a very high level in RBCs abolished the inhibitory function of the ASO, even the ASOs that could enter the cells; (3) the lower affinity of the locked nucleic acid (LNA/ DNA) miR-451 ASO might influence the formation of stable complexes with the blocking oligonucleotide [31]. Further investigations are required to delineate the relationship between $P$. falciparum infection and human miRNA accumulation in RBCs.

\section{Abbreviations}

siRNAs: short interfering RNAs; RISC: RNA-induced silencing complex; iRBCs: infected red blood cells; ASO: antisense oligonucleotide; WBC: white blood cells; has: Homo sapiens;LNA: locked nucleic acids

\section{Authors' contributions}

XX carried out the construction and analysis of small RNA library, participated in the analysis of miR-451 expression and drafted the manuscript. QZ carried out Northern blot of miR-451 expression. LF was involved in the identification of small RNA. YH was responsible for the culture of $P$. falciparum. WP made contribution to the conception and design, revised the manuscript and finally approved the version of the manuscript for publication. All authors read and approved the final manuscript.

\section{Acknowledgements}

This work is supported by grants from the National Basic Research Program (973 Program) in China (2007CB5 I 3 I00).

\section{References}

I. Bartel DP: MicroRNAs: genomics, biogenesis, mechanism, and function. Cell 2004, I 1 6:28I-297.

2. Reinhart BJ, Slack FJ, Basson M, Pasquinelli AE, Bettinger JC, Rougvie AE, Horvitz HR, Ruvkun G: The 2 I-nucleotide let-7 RNA regulates developmental timing in Caenorhabditis elegans. Nature 2000, 403:901-906.
3. Wightman B, Ha I, Ruvkun G: Posttranscriptional regulation of the heterochronic gene lin- 14 by lin-4 mediates temporal pattern formation in C. elegans. Cell 1993, 75:855-862.

4. Lagos-Quintana M, Rauhut R, Lendeckel W, Tuschl T: Identification of novel genes coding for small expressed RNAs. Science 200I, 294:853-858.

5. Lau NC, Lim LP, Weinstein EG, Bartel DP: An abundant class of tiny RNAs with probable regulatory roles in Caenorhabditis elegans. Science 200I, 294:858-862.

6. Lee RC, Ambros V: An extensive class of small RNAs in Caenorhabditis elegans. Science 200I, 294:862-864.

7. Ruby JG, Jan C, Player C, Axtell MJ, Lee W, Nusbaum C, Ge H, Bartel DP: Large-scale sequencing reveals 2 I U-RNAs and additional microRNAs and endogenous siRNAs in C. elegans. Cell 2006, | 27: | | 93-1207.

8. Carlton JM, Angiuoli SV, Suh BB, Kooij TW, Pertea M, Silva JC, Ermolaeva MD, Allen JE, Selengut JD, Koo HL, Peterson JD, Pop M, Kosack DS, Shumway MF, Bidwell SL, Shallom S], van Aken SE, Riedmuller SB, Feldblyum TV, Cho JK, Quackenbush J, Sedegah M, Shoaibi A, Cummings LM, Florens L, Yates JR, Raine JD, Sinden RE, Harris MA, Cunningham DA, et al.: Genome sequence and comparative analysis of the model rodent malaria parasite Plasmodium yoelii yoelii. Nature 2002, 4I 9:5 I2-5I9.

9. Gardner MJ, Hall N, Fung E, White O, Berriman M, Hyman RW, Carlton JM, Pain A, Nelson KE, Bowman S, Paulsen IT, James K, Eisen JA, Rutherford K, Salzberg SL, Craig A, Kyes S, Chan MS, Nene V, Shallom SJ, Suh B, Peterson J, Angiuoli S, Pertea M, Allen J, Selengut J, Haft $D$, Mather MW, Vaidya AB, Martin DM, et al.: Genome sequence of the human malaria parasite Plasmodium falciparum. Nature 2002, 41 9:498-5II.

10. Hall N, Karras M, Raine JD, Carlton JM, Kooij TW, Berriman M, Florens L, Janssen CS, Pain A, Christophides GK, James K, Rutherford K, Harris B, Harris D, Churcher C, Quail MA, Ormond D, Doggett J, Trueman HE, Mendoza J, Bidwell SL, Rajandream MA, Carucci DJ, Yates JR 3rd, Kafatos FC, Janse CJ, Barrell B, Turner CM, Waters AP, Sinden RE: A comprehensive survey of the Plasmodium life cycle by genomic, transcriptomic, and proteomic analyses. Science 2005, 307:82-86.

11. Crooke A, Diez A, Mason PJ, Bautista JM: Transient silencing of Plasmodium falciparum bifunctional glucose-6-phosphate dehydrogenase-6-phosphogluconolactonase. Febs J 2006, 273: $1537-1546$.

12. Gissot M, Briquet S, Refour P, Boschet C, Vaquero C: PfMybI, a Plasmodium falciparum transcription factor, is required for intra-erythrocytic growth and controls key genes for cell cycle regulation. J Mol Biol 2005, 346:29-42.

13. Malhotra P, Dasaradhi PV, Kumar A, Mohmmed A, Agrawal N, Bhatnagar RK, Chauhan VS: Double-stranded RNA-mediated gene silencing of cysteine proteases (falcipain-I and -2) of Plasmodium falciparum. Mol Microbiol 2002, 45: I245-1254.

14. McRobert L, McConkey GA: RNA interference (RNAi) inhibits growth of Plasmodium falciparum. Mol Biochem Parasitol 2002, I 1 9:273-278.

15. Mohmmed A, Dasaradhi PV, Bhatnagar RK, Chauhan VS, Malhotra P: In vivo gene silencing in Plasmodium berghei - a mouse malaria model. Biochem Biophys Res Commun 2003, 309:506-5 II.

16. Djikeng A, Shi H, Tschudi C, Ullu E: RNA interference in Trypanosoma brucei: cloning of small interfering RNAs provides evidence for retroposon-derived 24-26-nucleotide RNAs. Rna 200I, 7:1522-1530.

17. Mochizuki K, Gorovsky MA: Small RNAs in genome rearrangement in Tetrahymena. Curr Opin Genet Dev 2004, I4: I8I-I87.

18. De S, Pal D, Ghosh SK: Entamoeba histolytica: computational identification of putative microRNA candidates. Exp Parasitol 2006, I I 3:239-243.

19. Cerutti $\mathrm{H}$, Casas-Mollano JA: On the origin and functions of RNA-mediated silencing: from protists to man. Curr Genet 2006, 50:81-99.

20. Coulson RM, Hall N, Ouzounis CA: Comparative genomics of transcriptional control in the human malaria parasite Plasmodium falciparum. Genome Res 2004, 14:1548-1554.

21. Rathjen T, Nicol C, McConkey G, Dalmay T: Analysis of short RNAs in the malaria parasite and its red blood cell host. FEBS Lett 2006, 580:5 I85-5I88. 
22. Ljungström IPH, Schichtherle M, Scherf A, Wahlgen M: Methods in Malaria Research. Fourth edition. Manassas, Virginia MR4/ATCC; 2004.

23. GenBank [http://www.ncbi.nih.gov/Genbank/index.html]

24. The P. falciparum genome database [http://www.sanger.ac.uk/ cgi-bin/blast/submitblast/p falciparum]

25. Human tRNA database [http://rna.wustl.edu/GtRDB/Hs/Hsseqs.html]

26. miRNAs database [http://www.sanger.ac.uk/Software/Rfam/ mirna]

27. RNA-fold software [http://www.bioinfo.rpi.edu/applications/ mfold]

28. Chan JA, Krichevsky AM, Kosik KS: MicroRNA-2 I is an antiapoptotic factor in human glioblastoma cells. Cancer Res 2005, 65:6029-6033.

29. Elmen J, Lindow M, Silahtaroglu A, Bak M, Christensen M, Lind-Thomsen A, Hedtjarn M, Hansen JB, Hansen HF, Straarup EM, McCullagh K, Kearney P, Kauppinen S: Antagonism of microRNA-I 22 in mice by systemically administered LNA-antimiR leads to up-regulation of a large set of predicted target mRNAs in the liver. Nucleic Acids Res 2007 in press.

30. Orom UA, Kauppinen S, Lund AH: LNA-modified oligonucleotides mediate specific inhibition of microRNA function. Gene 2006, 372:137-14I.

31. Davis S, Lollo B, Freier S, Esau C: Improved targeting of miRNA with antisense oligonucleotides. Nucleic Acids Res 2006, 34:2294-2304.

Publish with Biomed Central and every scientist can read your work free of charge

"BioMed Central will be the most significant development for disseminating the results of biomedical research in our lifetime. "

Sir Paul Nurse, Cancer Research UK

Your research papers will be:

- available free of charge to the entire biomedical community

- peer reviewed and published immediately upon acceptance

- cited in PubMed and archived on PubMed Central

- yours - you keep the copyright

Submit your manuscript here:

http://www.biomedcentral.com/info/publishing_adv.asp
BiolMedcentral 